2018-10

Early withdrawal from higher education: A focus on academic experiences

\title{
Webb, OJ
}

http://hdl.handle.net/10026.1/10567

10.1080/13562517.2018.1437130

Teaching in Higher Education

Taylor \& Francis (Routledge)

All content in PEARL is protected by copyright law. Author manuscripts are made available in accordance with publisher policies. Please cite only the published version using the details provided on the item record or document. In the absence of an open licence (e.g. Creative Commons), permissions for further reuse of content should be sought from the publisher or author. 
Early withdrawal from higher education: A focus on academic experiences

O.J. Webb* and D.R.E. Cotton*

*Pedagogic Research Institute and Observatory, University of Plymouth, Plymouth, United Kingdom, PL4 8AA, +44 1752584529

Corresponding author: Dr. O.J. Webb (oliver.webb@plymouth.ac.uk)

Word count (excluding references list): 6105

Abstract word count: 141 


\begin{abstract}
Early withdrawal from higher education (HE) programmes can be detrimental for the students and institutions involved. Quantitative research has often concentrated on demographic and social antecedents (e.g. gender, prior education). Other factors may be more open to intervention e.g. students' academic experiences in HE. Using data from an institutional survey $(\mathrm{N}=1170)$, logistic regression tested a range of academic experiences, regarding their relationship to contemplation of withdrawal (' $\mathrm{COW}$ ': a recognized marker for actual withdrawal). COW was associated with student perceptions of low one-to-one contact with staff; non-traditional delivery methods; low peer-interaction; and high assessment load. Interestingly, COW was not associated with overall contact hours, large classes, or personal tutoring. The contributing factors explained $5.1 \%-8.6 \%$ of variance in $\mathrm{COW}$, suggesting they may be meaningful levers for optimizing retention. The paper discusses links to existing literature, future research directions, and applied implications for institutions.
\end{abstract}

Key words: Attrition, drop-out, retention, non-completion, withdrawal 


\section{Introduction}

Typically, entrants to higher education (HE) register on a specified programme, giving a clear intention of the qualification they seek to attain. Monitoring the proportion of students who are successful towards this goal is both important and challenging. Thomas and Quinn (2007) describe 20 different terms covering the completion of a degree within a set time frame. These concepts differ in how well they capture a range of student narratives (Thomas and Hovdhaugen 2014 and van Stolk et al. 2007). For example, retention (and its opposite, attrition) is generally understood to describe whether students stay at a given institution. Leavers who take up study elsewhere are not differentiated from those who depart HE permanently. By contrast, the concept of completion (and its opposite, non-completion) is less institutionally-focussed. It recognises students who complete a programme within a given time frame, either through sustained study at a single institution or participation at multiple institutions. In this way, completion better recognises the portability of credit in modern HE. However, neither approach satisfactorily records individuals who abort studies but return after a sustained absence to successfully complete a programme. Compounding these conceptual differences, there can be technical nuances in how measures of retention and completion are operationalised. For example, countries differ in the time limits used to define completion; the exclusion of certain groups (e.g. part time students); and the use of full cohort versus cross-sectional data. Notwithstanding these complexities, best estimates show non-completion to be a significant phenomenon, affecting up to 54\% of HE entrants in some EU states (Quinn 2013). Furthermore, risk of withdrawal is higher amongst underrepresented groups (e.g. ethnic minorities; Quinn 2013), with potential to exacerbate existing inequalities in participation.

In some instances withdrawing from study can be positive, enabling the individual to pursue more rewarding opportunities. Some countries (e.g. Belgium) wittingly operate a model of 
mass HE enrolment, whereby the early stages (e.g. year one) serve to filter out those who are less able or motivated to persist. Nonetheless, withdrawal can have negative consequences. For example, bereft of the intended qualification, individuals may face significant financial debt, even where attendance lasted a matter of weeks. In addition, McGiveny (1996) describes an association between withdrawal and feelings of inadequacy, which may persist into later life.

For Higher Education Institutions (HEIs), which rely on student fees for income, the withdrawal of learners leaves a financial void. Statistics on student retention are also factored into influential league tables (e.g. the UK's Times and Sunday Times Good University Guide). Amongst six core metrics, the UK's Teaching Excellence Framework includes HEIs' retention rate, benchmarked to take account of student composition (HEFCE 2016). It is proposed that the results of this nationwide assessment will determine the level of fees that each institution can charge.

There is a long history of theorising about factors associated with completion/retention. According to Tinto's seminal Interactionist Model (1975), retention is driven by how well students integrate into university life, both in academic terms (e.g. as measured by enjoyment of and performance in academic studies) and social terms (e.g. as measured by number of friendships forged and frequency of interactions with faculty members). The model pays reference to important moderating factors (e.g. family background). Nonetheless, some feel that it under-estimates how students' persistence and success are influenced by their familiarity with elite cultural codes that play out in HEIs. Thus, investigators have used Bourdieu's (1986) concept of cultural capital as a lens for studying student retention (e.g. Longden 2004). Whilst it is challenging to derive explicit measures of cultural capital, certain factors offer a proxy (e.g. parental engagement in HE, type of prior educational establishment; Whitty, Hayton, and Tang 2015). Over time, Bourdieusien approaches have 
themselves been challenged as overly-deterministic; differential outcomes are, after all, observed amongst students with seemingly similar life circumstances (Cotton, Nash, and Kneale 2017). As investigators have sought a comprehensive understanding of withdrawal, they have examined ever more diverse factors, including motivation (Robbins et al. 2004), psychological health (Charlton, Barrow and Hornby-Atkinson 2006), and emotional resilience (Cotton, Nash, and Kneale 2017).

Several publications have reviewed factors associated with withdrawal (e.g. NAO 2007; Thomas 2002). Usefully, Thomas (2002) defined broad headings under which these predictors might be arranged: (i) academic preparedness; (ii) academic experiences; (iii) institutional expectations and commitment; (iv) academic and social match; (v) finance and employment; (vi) family support and commitments; and (vii) university support services. To inform policies and initiatives around withdrawal, there have been calls to go beyond mere categorisation of factors. Thomas and Hovdhaugen's (2014 466) statement that predictors need to be 'collected, categorised, and ranked in importance', suggests a possible role for quantitative methods.

Several studies have seized upon sector-wide datasets of student characteristics and outcomes collected by regulatory agencies such as the Universities and Colleges Admissions Service in the UK. Using quantitative techniques (e.g. logistic regression), the strength of association between different factors and withdrawal has been explored (e.g. Arulampalam, Naylor, and Smith 2005; Rose-Adams 2012). Potentially valuable findings have emerged. For example, using data from 86 UK HEIs Rose-Adams (2013) found that withdrawal is more likely in students who are male; mature; from neighbourhoods with little HE participation; graduates of a further education college; without recent A-levels; in possession of fewer tariff points; and resident within 30 miles of their HEI. Such studies benefit from vast, representative samples. Nonetheless, their scope is limited to those variables which are routinely collected 
by regulatory bodies (e.g. demographics). There is less coverage of the factors in Thomas's (2002) taxonomy.

For HEIs that are tackling early withdrawal as a matter of priority, there may be reason to concentrate efforts in specific areas. In particular, academic experiences may be more open to local intervention, as compared with demographic characteristics and other categories identified by Thomas (2002). Furthermore, empirical evidence alludes to potentially powerful relationships with withdrawal. Having observed considerable inter-faculty variance in the withdrawal rate at one HEI, Charlton, Barrow and Hornby-Atkinson (2006) cited differences in instructional style, teaching quality and learning culture as potential explanatory mechanisms. A project from the What Works? Student Retention \& Success programme (Thomas 2012a) also reported course-related factors as the primary reason for students contemplating withdrawal. After accounting for other factors (e.g. socio-economic status, high school GPA) a meta-analysis by Robbins et al. (2004) found a significant association between retention and academic-related skills, which was larger than for other psychosocial factors (e.g. social support, social involvement, and academic goal setting). Academic experiences are important as they are likely to influence students' development of academicrelated skills. For example, programmes which incorporate discursive teaching methods, opportunities for group work, and one-to-one contact with teaching staff, are likely to benefit communication skills. Meanwhile, exchanges with personal tutors may be valuable in honing coping skills.

Using quantitative methods to control for known demographic predictors, the current study examined students' contemplation about withdrawing from their course, in relation to perceptions of specific academic experiences (e.g. class sizes; use of technology-enhanced learning; one-to-one time with lecturers). Common with much research in this domain (e.g. Thomas 2002), the study used a prospective approach that asked current students about the 
possibility of future withdrawal. This differs from the concepts of retention and completion discussed earlier, which rely on knowledge of actual student outcomes. Consequently, a distinguishing term - early withdrawal - is used throughout. The overarching aim is to filter a range of academic experiences down to those with the strongest links to contemplation of withdrawal. These might form the focus of further work to demonstrate causal relationships.

\section{Methods}

Ethical approval was granted by the internal committee of the host HEI; a large, public university in Southern England, which belongs to the post-1992 group. The study made use of the institution's Teaching and Learning Survey (TLS), an extensive e-questionnaire featuring items which map onto Thomas's (2002) headings. In 2013 and 2014 all undergraduate first years were invited to complete the TLS via Survey Monkey, with access open from March to May of both years. No individual responded more than once (i.e. where 2013 respondents repeated their first year in 2014, the later data were excluded). To optimise statistical power, both years' data were collapsed for analysis $(\mathrm{N}=1170)$, representing a net response rate of $10 \%$.

The dependent variable was the binary item 'Have you considered withdrawing from your course?', or COW for short (contemplation of withdrawal). Empirical evidence indicates that COW is a significant predictor of actual withdrawal (see Willcoxson, Cotter, and Joy 2011). To test this assumption in the current data, institutional records were used to establish each respondent's actual withdrawal behaviour, as accurate until the start of the 2015/16 academic year. At minimum, this tracked individuals to the end of their second year; a window in which much withdrawal might be expected to have occurred. Chi-square was used to compare actual withdrawal against COW. 
Logistic regression was used to identify predictors with significant associations to COW. A first block of predictors included two demographic variables that were important in previous research (gender and age). To gauge the representativeness of the current sample, these demographics were compared against figures for the whole institution, as submitted to the Higher Education Statistics Agency. A second block comprised 15 items from the TLS that addressed specific academic experiences (see Table 1). Initially, items C, F, G and M had three response options. Certain options were, however, rarely selected by respondents (e.g. 'too little'). Consequently, they were combined with 'about right' in each case. Others items employed a five-point Likert-type scale e.g. strongly agree - strongly disagree, with a neutral midpoint. For ease of analysis and interpretation, the later were collapsed into three response options (e.g. strongly agree + agree; neutral; strongly disagree + disagree). They were treated as categorical variables.

A block entry approach was used whereby all models retained the first block of predictors. The second block of predictors was entered using backward elimination, in which predictors that do not make a significant contribution to the overall model are progressively removed. Pvalues for entry and removal were both set at $p<.10$ and $90 \%$ confidence intervals (CIs) were generated. Whilst backward elimination has attracted some criticism, it is justifiable in the exploratory phases of enquiry where there is little theory or evidence to inform the selection of predictors (Field 2005). Since there is no known data on the specific academic experiences explored in the current data set, this provides a suitable approach and is preferable to the alternative of forward selection, as it is less prone to type II errors (Field 2005). 


\section{Table 1. Descriptives for demographics, academic experiences, and contemplation of withdrawal (COW)}

\begin{tabular}{|c|c|c|c|c|c|c|c|}
\hline & & \multirow{3}{*}{ Predictor } & \multirow{3}{*}{ Response Options } & \multicolumn{4}{|c|}{ Contemplation of Withdrawal (CoW) } \\
\hline & & & & \multicolumn{2}{|c|}{$\%$} & \multicolumn{2}{|c|}{ n } \\
\hline & & & & Yes & No & Yes & No \\
\hline \multirow{4}{*}{$\begin{array}{c}\text { Block 1: } \\
\text { Demographics }\end{array}$} & $\mathrm{A}$ & Gender & Male, & $15 \%$ & $85 \%$ & 62 & 363 \\
\hline & & & Female & $15 \%$ & $85 \%$ & 96 & 530 \\
\hline & $\mathrm{B}$ & Age & $<21$ & $14 \%$ & $87 \%$ & 102 & 651 \\
\hline & & & $\geq 21$ & $19 \%$ & $81 \%$ & 57 & 240 \\
\hline \multirow{41}{*}{$\begin{array}{c}\text { Block 2: } \\
\text { Academic } \\
\text { Experiences }\end{array}$} & $\mathrm{C}$ & 'Do you think the number of contact hours is...' & About right / Too much, & $14 \%$ & $86 \%$ & 105 & 643 \\
\hline & & & Too little & $21 \%$ & $79 \%$ & 53 & 199 \\
\hline & $\mathrm{D}$ & 'The teaching on my programme is mainly based & (Strongly) agree, & $15 \%$ & $85 \%$ & 105 & 589 \\
\hline & & on lectures' & Neutral, & $14 \%$ & $86 \%$ & 14 & 84 \\
\hline & & & (Strongly) disagree & $20 \%$ & $80 \%$ & 40 & 160 \\
\hline & $\mathrm{E}$ & 'There is too little use of technology for teaching & (Strongly) agree, & $21 \%$ & $79 \%$ & 32 & 119 \\
\hline & & and learning' & Neutral, & $19 \%$ & $81 \%$ & 56 & 241 \\
\hline & & & (Strongly) disagree & $13 \%$ & $87 \%$ & 70 & 471 \\
\hline & $\mathrm{F}$ & 'Do you feel your course/programme of study & About right / Too much, & $15 \%$ & $85 \%$ & 117 & 687 \\
\hline & & allows you enough interaction with other students?' & Too little & $23 \%$ & $77 \%$ & 42 & 142 \\
\hline & $\mathrm{G}$ & 'The quantity of assessment on your course is...' & About right / Too little, & $14 \%$ & $86 \%$ & 123 & 731 \\
\hline & & & Too much & $26 \%$ & $74 \%$ & 36 & 101 \\
\hline & $\mathrm{H}$ & 'Is the feedback helpful?' & Always/usually, & $14 \%$ & $86 \%$ & 92 & 585 \\
\hline & & & Sometimes, & $21 \%$ & $79 \%$ & 52 & 197 \\
\hline & & & Rarely/never & $24 \%$ & $76 \%$ & 15 & 47 \\
\hline & $\mathrm{I}$ & 'Have the following been problematic?' & (Strongly) agree, & $18 \%$ & $82 \%$ & 55 & 249 \\
\hline & & 'Large classes' & Neutral, & $19 \%$ & $81 \%$ & 46 & 198 \\
\hline & & & (Strongly) disagree & $13 \%$ & $87 \%$ & 57 & 384 \\
\hline & $\mathrm{J}$ & 'Academic language/terminology' & (Strongly) agree, & $20 \%$ & $80 \%$ & 73 & 293 \\
\hline & & & Neutral, & $17 \%$ & $83 \%$ & 35 & 175 \\
\hline & & & (Strongly) disagree & $12 \%$ & $88 \%$ & 48 & 364 \\
\hline & $\mathrm{K}$ & 'The need for so much independent learning' & (Strongly) agree, & $20 \%$ & $80 \%$ & 98 & 400 \\
\hline & & & Neutral, & $15 \%$ & $75 \%$ & 24 & 135 \\
\hline & & & (Strongly) disagree & $11 \%$ & $89 \%$ & 35 & 296 \\
\hline & $\mathrm{L}$ & 'The lack of 1 to 1 contact with teaching staff' & (Strongly) agree, & $22 \%$ & $78 \%$ & 100 & 346 \\
\hline & & & Neutral, & $13 \%$ & $87 \%$ & 24 & 156 \\
\hline & & & (Strongly) disagree & $9 \%$ & $91 \%$ & 34 & 324 \\
\hline & $\mathrm{M}$ & 'Do you feel the number of meetings with your & About right / Too much, & $13 \%$ & $87 \%$ & 75 & 490 \\
\hline & & personal tutor is...' & Too little & $22 \%$ & $79 \%$ & 71 & 259 \\
\hline & $\mathrm{N}$ & 'My personal tutor is approachable' & (Strongly) agree, & $15 \%$ & $85 \%$ & 108 & 619 \\
\hline & & & Neutral, & $24 \%$ & $76 \%$ & 23 & 72 \\
\hline & & & (Strongly) disagree & $20 \%$ & $80 \%$ & 13 & 51 \\
\hline & $\mathrm{O}$ & 'My personal tutor is encouraging' & (Strongly) agree, & $15 \%$ & $85 \%$ & 98 & 553 \\
\hline & & & Neutral, & $20 \%$ & $80 \%$ & 35 & 138 \\
\hline & & & (Strongly) disagree & $18 \%$ & $82 \%$ & 10 & 46 \\
\hline & $\mathrm{P}$ & 'My personal tutor gives me useful advice' & (Strongly) agree, & $14 \%$ & $86 \%$ & 93 & 549 \\
\hline & & & Neutral, & $21 \%$ & $79 \%$ & 34 & 131 \\
\hline & & & (Strongly) disagree & $22 \%$ & $78 \%$ & 17 & 60 \\
\hline & $\mathrm{Q}$ & 'My personal tutor is comfortable discussing non- & (Strongly) agree, & $14 \%$ & $86 \%$ & 69 & 424 \\
\hline & & academic issues' & Neutral, & $19 \%$ & $81 \%$ & 61 & 266 \\
\hline & & & (Strongly) disagree & $23 \%$ & $77 \%$ & 14 & 48 \\
\hline
\end{tabular}

Alongside the items from Table 1, the TLS featured three relevant contextual questions. Two questions covered, respectively, the timing and motivation regarding $\mathrm{COW}$, and had predefined response options (Table 2 and 3 ). The third question invited respondents to make open-ended comments: 'What other support and services would you like from your personal tutor?'. 
Table 2. Timing of thoughts about withdrawal or changing course/institution

\begin{tabular}{|l|c|}
\hline $\begin{array}{c}\text { 'When have you contemplated } \\
\text { withdrawal/changing course/changing } \\
\text { institution?' (tick all that apply) }\end{array}$ & $\mathbf{N}$ \\
\hline Before starting at the university & 21 \\
\hline In the first two weeks of university & 38 \\
\hline During the first term & 132 \\
\hline Returning after Christmas & 125 \\
\hline Now & 84 \\
\hline
\end{tabular}

Table 3. Reasons for contemplating withdrawal or a change of course/institution

\begin{tabular}{|c|l|c|}
\hline Rank & $\begin{array}{c}\text { 'What is your main reason for contemplating withdrawal/changing } \\
\text { course/changing institution' }\end{array}$ & $\mathbf{N}$ \\
\hline 1 & Financial concerns & 86 \\
\hline 2 & Became interested in another course & 84 \\
\hline 3 & Not coping with academic work & 79 \\
\hline 4 & Feeling unsupported & 74 \\
\hline 5 & Dissatisfied with quality of teaching & 70 \\
\hline 6 & Feeling homesick & 65 \\
\hline 7 & Dissatisfied with quality of the student experience & 53 \\
\hline 8 & Family difficulties & 51 \\
\hline 9 & Poor choice of course & 50 \\
\hline 10 & Social difficulties & 44 \\
\hline 11 & Health difficulties & 43 \\
\hline 12 & My timetable & 37 \\
\hline 13 & Travel difficulties & 36 \\
\hline 14 & Accommodation difficulties & 28 \\
\hline
\end{tabular}

\section{Results}

After the exclusion of repeat respondents, the data set comprised 1170 individuals. In terms of demographics, values for the cohort (underscored) were similar to institutional figures (female, $\underline{60 \%}$ versus $61 \%$; $<21$ years, $\underline{72 \%}$ versus $68 \%$ ). Respondents were drawn from across the host institution's five faculties and 18 schools. Amongst 1052 participants who responded to the COW item, $15 \%$ indicated that they had contemplated withdrawal. Analyses confirmed a significant association between COW and actual withdrawal $\left(\chi^{2}[1, N=1052]=\right.$ $13.10, p<.001)$, although incidence of actual withdrawal $(\mathrm{n}=34)$ was lower than the number of students who contemplated it. The Phi co-efficient (.11) represented a small significant effect size according to Cohen (1988). Table 2 shows the times when respondents contemplated withdrawing or changing course/institution. Whilst this was most likely to occur between the third week of registration and the end of the first term, it was also common on return from the Christmas holiday and during the survey window itself (March-May). 
Table 3 lists respondents' main reasons for contemplating withdrawal or a change of course/institution. Academic experiences appear to be central to responses \#3, \#5 and \#12, and might also contribute in the case of \#4 and \#7.

Table 1 provides descriptive information for all items. Within logistic regression, all data for a respondent is excluded where he/she has a missing value for any variable. Hence, the sample size included in the logistic regression $(\mathrm{N}=837)$ was smaller than the total cohort.

As shown in Table 1, the proportion of respondents answering 'yes' to COW was consistent between genders. COW was more common in respondents aged $\geq 21$ years compared to their younger counterparts, as confirmed by the logistic regression (Table 4). The odds ratio [OR] suggests that older respondents were 1.4 times more likely to contemplate withdrawal. When Block 2 was added, several predictors were unrelated to $\mathrm{COW}$ and thus eliminated from the model. Nonetheless, descriptive data for these excluded items offers an insight to students' general perceptions. Aggregating the 'Yes' and 'No' columns in Table 1, the raw volume of respondents who (strongly) disagreed that large classes were problematic (Predictor I: 441 or $45 \%$ ) surpassed those who (strongly) agreed (304 or 31\%). Similarly, the proportion of respondents who (strongly) disagreed that academic language/terminology was problematic (Predictor J) was greater than those who (strongly) agreed (42\% vs 37\%). Whilst broadly positive, these figures suggest that a sizeable minority of students identify these two academic experiences as difficult. The distribution of scores for predictors $\mathrm{E}, \mathrm{H}$ and $\mathrm{K}$ is more marked (Table 1). Respectively, these results indicate that a majority of respondents reject the idea that the current use of learning technology is insufficient (Predictor E: 70\% [strongly] disagree vs. 15\% [strongly] agree); find feedback on work helpful in the majority of instances (Predictor H: 69\% [strongly] agree vs. 6\% [strongly] disagree); and report independent learning as challenging (Predictor K: 50\% [strongly] agree vs. 34\% [strongly] disagree). 
Table 4. Results from logistic regression analysis

\begin{tabular}{|c|c|c|c|c|c|c|c|c|}
\hline & & \multirow{2}{*}{\multicolumn{2}{|c|}{ Predictor }} & \multirow{3}{*}{$\begin{array}{l}\begin{array}{l}\text { Odds } \\
\text { Ratio }\end{array} \\
1.012\end{array}$} & \multirow{3}{*}{$\begin{array}{c}\text { 90\% Confidence } \\
\text { Intervals }\end{array}$} & \multirow{2}{*}{$P$ value } & \multicolumn{2}{|c|}{$\mathbf{R}^{2}$} \\
\hline & & & & & & & Cox \& Snell & Nagelkerke \\
\hline \multirow{2}{*}{$\begin{array}{c}\text { Block 1: } \\
\text { Demographics }\end{array}$} & A & Gender & Male vs. Female & & & .953 & \multirow[b]{2}{*}{.005} & \multirow[b]{2}{*}{.008} \\
\hline & $\mathrm{B}$ & Age & $\geq 21$ years vs. $<21$ years & 1.427 & $1.019-1.999$ & .082 & & \\
\hline \multirow{4}{*}{$\begin{array}{c}\text { Block 2: } \\
\text { Academic } \\
\text { Experiences }\end{array}$} & $\mathrm{D}$ & $\begin{array}{l}\text { 'The teaching on my programme is mainly based } \\
\text { on lectures' }\end{array}$ & $\begin{array}{l}\text { Neutral } \\
\text { (Strongly) agree } \\
\text { (Strongly) disagree }\end{array}$ & $\begin{array}{l}1.000 \\
1.306 \\
2.338\end{array}$ & $\begin{array}{l}0.696-2.452 \\
1.181-4.627\end{array}$ & $\begin{array}{l}.486 \\
.041\end{array}$ & \multirow{4}{*}{.051} & \multirow{4}{*}{.086} \\
\hline & $\mathrm{F}$ & $\begin{array}{l}\text { 'Do you feel your course/programme of study } \\
\text { allows you enough interaction with other students?' }\end{array}$ & $\begin{array}{l}\text { Too little vs. } \\
\text { About right / Too much }\end{array}$ & 1.516 & $1.050-2.189$ & .062 & & \\
\hline & G & 'The quantity of assessment on your course is...' & $\begin{array}{l}\text { Too much vs. } \\
\text { About right / Too little }\end{array}$ & 1.618 & $1.078-2.427$ & .051 & & \\
\hline & $\mathrm{L}$ & $\begin{array}{l}\text { 'Have the following been problematic?' } \\
\text { 'The lack of } 1 \text { to } 1 \text { contact with teaching staff' }\end{array}$ & $\begin{array}{l}\text { Neutral } \\
\text { (Strongly) agree } \\
\text { (Strongly) disagree }\end{array}$ & $\begin{array}{l}1.000 \\
1.780 \\
0.621\end{array}$ & $\begin{array}{l}1.131-2.799 \\
0.327-1.052\end{array}$ & $\begin{array}{l}.036 \\
.137\end{array}$ & & \\
\hline
\end{tabular}


Scores for predictors N-P suggest strong agreement that personal tutors are approachable (82\% [strongly] agree), encouraging (74\% [strongly] agree) and offer useful advice (73\% [strongly] agree). Recognition that personal tutors are comfortable discussing non-academic matters was more muted (Predictor Q: 56\% [strongly] agree). The two remaining nonsignificant predictors $(\mathrm{C}, \mathrm{M})$ relate to staff contact. Respectively, around $25 \%$ of respondents felt the number of contact hours was too little, and $37 \%$ felt the number of meetings with their personal tutor was insufficient. In terms of additional support that students would like from personal tutors, the open-ended question generated several responses concerning direct assistance with assignments e.g.:

- 'one-to-one feedback on all coursework so that I can get a second opinion'

- 'pre-reading assignments'

- '...go through draft essays to make sure I am on the right lines'

- 'when writing essays would be helpful to have a session to ensure were on the right track'

Amongst the predictors retained from Block 2, COW was associated with a perceived lack of one-to-one contact with teaching (predictor L). Whereas there was no significant difference between those who (strongly) disagreed and those with neutral perceptions, relative to the latter respondents who (strongly) agreed were more likely to report COW (Table 4; odd ratio $[\mathrm{OR}]=1.780)$. In raw percentage terms $22 \%$ of this group contemplated COW versus $13 \%$ of those with neutral views and just $9 \%$ of respondents who (strongly) disagreed that the level of one-to-one contact was problematic (Table 1).

There were further associations between $\mathrm{COW}$ and two binary predictors ( $\mathrm{F}$ and $\mathrm{G}$ ). $\mathrm{COW}$ was more likely in respondents who identified too little opportunity for interacting with fellow students $(23 \%)$ versus all others (15\%). Logistic regression confirmed a significant 
effect $(\mathrm{OR}=1.516)$. Incidence of COW was also higher in those perceived too much assessment than those who did not ( $26 \%$ vs. $14 \%$; OR=1.618).

Finally, an intriguing effect emerged concerning perceptions of teaching as mainly lecturebased. No significant difference in COW between neutral respondents (14\%) and those who (strongly) agreed (15\%) contrasted with significantly higher likelihood of COW in those who (strongly) disagreed (20\%) versus neutral respondents $(\mathrm{OR}=2.338)$.

Demographic variables alone accounted for $0.5-0.8 \%$ of the variance in COW, dependant on the variant of $\mathrm{R}^{2}$ chosen (Table 4). With the addition of the items in the second block, this rose to $5.1-8.6 \%$.

\section{Discussion}

The current study examined students' proclivity for considering withdrawal from their university course, in relation to specific, potentially modifiable, academic experiences. The use of quantitative techniques to assess different aspects of the academic context is novel. Controlling for known demographic predictors, several factors were associated with contemplation of withdrawal, which was itself a significant predictor of actual withdrawal. These were:

- Students' perception that one-to-one contact with teaching staff was low.

- Students' reports that lectures were not the main teaching format.

- Students' perception that opportunities to interact with fellow students were low.

- Students' reports that the volume of assessment was excessive.

Results for demographic variables were partially consistent with previous research. COW was more common amongst respondents aged $\geq 21$ years. This replicates previous findings for mature students who, according to Rose-Adams (2012), may have existing financial and 
family commitments, which heighten the risk of withdrawal. Conversely, COW was stable across genders. This contrasts with previous literature reporting a greater risk of withdrawal amongst men. One explanation for this divergence may lie in the role of moderating factors. For example, in the Back on Course study gender effects depended on student entry tariffs (Rose-Adams 2012), information which was not captured by the TLS.

\section{One-to-one contact with teaching staff}

The findings suggest an important theme around access to academic staff. Regression analyses confirmed that COW was significantly associated with the perceived adequacy of one-to-one contact with teaching staff. For respondents who (strongly) agreed that this aspect of their academic experiences had been problematic, the likelihood of considering withdrawal was more than twice that of counterparts who (strongly) disagreed (22\% vs. 9\%). Research within target groups who are at higher risk of withdrawal confirms the importance of one-toone exchanges. Cotton, Nash, and Kneale (2014) describe how a relationship with a trusted university figure can benefit care leaving students (i.e. those who have been in foster care or care of the local state/authority shortly prior to HE). Meanwhile, in a US context Soria and Stebleton (2012) discuss a reluctance amongst first generation students to ask lecturers questions in front of the class. Efforts to support students in comparing and selecting HE courses (e.g. the UNISTATS website) may be compromised by the tendency to present overall contact hours, without further granularity showing one-to-one support. Sector-wide instruments (e.g. the UK's National Student Survey) lack precision to chart student evaluations of one-to-one staff contact over a number of years. Individual longitudinal studies have, however, uncovered a deterioration in these appraisals over time (Giannakis and Bullivant 2016). There is support for continued research into the teacher-student relationship in HE (Hagenauer and Volet 2014; Richardson and Radloff 2014). 
Assuming that one-to-one contact with staff has a causal influence on COW, attention turns to 'how the curriculum might be reorganised to provide for sustained engagement between teachers and students' (Thomas 2012b 1). The personal tutoring space offers an obvious opportunity. Amongst current respondents, $37 \%$ felt the number of meetings with their personal tutor was too low. This corresponds closely with the $42 \%$ of respondents to a national survey, who selected more contact with personal tutors as a means of improving the quality of the university learning and teaching experience (NUS 2012). It is interesting, however, that COW was not directly associated with respondents' views on the volume of personal tutor contact or their tutors' qualities. Whilst personal tutoring is valued by students, it may not be the most instrumental academic experience regarding the particular phenomenon of withdrawal. Such subtleties suggest a need for further qualitative work, to examine which type(s) of one-to-one support might be most protective against withdrawal and why.

Despite the non-significant findings for personal tutoring, the open-ended suggestions as to what support students would, ideally, receive from their personal tutors, are insightful. Several showed a desire for direct support with assignments. This follows national research about teaching characteristics most strongly correlated with student satisfaction, in which four of the top ten responses relate to feedback and guidance ('teaching staff gave you useful feedback'; 'teaching staff put a lot of time into commenting on your work'; 'teaching staff were open to having further discussions about your work'; 'teaching staff gave you feedback in time to help with the next assignment'; Neves and Hillman 2016). There are challenges in meeting these aspirations via personal tutoring. Many HEIs have policies dissuading personal tutors from giving detailed feedback on work set by others, on grounds that they lack necessary sub-disciplinary knowledge or might undermine colleagues' academic judgement. Furthermore, in the 'traditional model' (Earwalker 1992), that places personal tutoring 
outside the formal curriculum, student engagement is optional and, as a consequence, variable. Thomas (2012b 9) recommends that approaches to enhancing retention should be 'embedded into mainstream provision to ensure that all students participate and benefit from them'. Forms of personal tutoring, which operate in many HEIs, may struggle to fulfil students' appetite for focussed input around their assignments.

One-to-one support may need to occur beyond the personal tutoring space, therefore, with opportunities ensured at module level. Regarding who is best placed to provide this support, data from nine Australian HEIs is enlightening (Richardson and Radloff 2014). Alongside strong evidence of a systematic association between departure intentions (a close relative of COW) and perceived quality of staff-student relationships, the authors found that many oneto-one exchanges involve casual or sessional teachers. Whilst these individuals can be highly capable of addressing students queries or requests, they may lack sufficient status to enact relevant changes to policy, curriculum or pedagogy, which would benefit the student body more broadly.

Ensuring one-to-one access to lecturing staff is challenging set against the massification that is occurring in HE systems around the globe (British Council 2014). Whilst technology can provide for more flexible approaches to delivery, it does not replace personalised input from lecturers. In terms of how to ensure one-to-one exchanges, within available resources, important nuances of the current study should be considered. Guidance accompanying the TLS clarified contact hours as 'timetabled hours for attending lectures, seminars, tutorials, practicals, fieldwork etc'. As such, predictor C probed whether respondents were satisfied with the composite level of staff contact, experienced across varied settings. Around three quarters of respondents were satisfied. Furthermore, COW was not associated with overall contact hours per se. There is a parallel here with Gibbs' (2010) observations about learning gain, whereby close contact with teaching staff was highly beneficial, irrespective of total 
contact hours. It may be that a modest schedule of overall contact is appropriate, provided that it involves opportunities to interact with teaching staff on a one-to-one basis. Given that the majority of respondents were not perturbed by large classes, a polarised pattern of delivery might be imagined, with attendance at very large (and therefore cost-effective) lectures interspersed with one-to-one support. Although Gibbs found large classes to be predictive of worse student performance, he described how a single HE programme can utilise a range of learning environments: 'In school, students may experience all their classes as much the same size. In higher education what may matter most is not the size of the largest lecture that is attended on any particular course but the size of the smallest seminar group or problem class that they attend within the same course' (Gibbs 2010 20). By extension, what might matter most in relation to retention, is not the size of the largest lecture but the frequency and quality of one-to-one interactions with lecturing staff.

\section{Lectures as the atypical teaching format}

Having noted that students strongly valued one-to-one contact with teaching staff, it might seem counter-intuitive that those who reported lectures as the dominant format were least likely to contemplate withdrawal. One might assume that alternative, more interactive teaching methods give students the best opportunities to work closely with lecturers and gain direct advice on assignments. Indeed, when asked in a recent survey about how to improve the university learning and teaching experience, respondents' most popular suggestion was more interactive group teaching sessions/tutorials (NUS 2012).

One explanation for this finding could be that students enter HE anticipating extensive participation in lectures. They may then find it difficult to adjust, should they encounter a divergent reality. Evidence around transitions into HE shows that, alongside appropriate study skills, accurate expectations of university-level study are crucial for developing positive 
self-efficacy (Christie, Barron and D'Annunzio-Green 2013). Where concerted efforts have been made to embed non-traditional (i.e. not lecture-based) pedagogies in the first year of undergraduate programmes, evaluation suggests that student expectations should be carefully managed (Turner et al. 2017). Strong induction processes can help students set realistic expectations regarding the teaching approaches they will encounter, as well as the methods and timescale by which they can gain feedback on assignments. Indeed, efforts to establish appropriate expectations could start even earlier through, for example, institutional outreach work. Such activities may have the additional benefit of forging a sense of commitment not merely to the notion of HE per se but to a particular HEI. The latter is significant with regard to retention (e.g. Berger and Braxton 1998). Since the cessation of Aim Higher, which had a focus on widening participation, the UK has had no substantive national programme to fund HE outreach activities (McCaig 2016; Webb, Wyness and Cotton 2017). With mounting evidence regarding the importance of accurate student expectations, this might be an area where individual HEIs should increase their activity.

\section{Opportunities to interact with fellow students}

Respondents who perceived too few opportunities to engage with fellow students were more likely to consider withdrawal. There are strong theoretical grounds for promoting peer interactions amongst students. Masika and Jones (2016) describe efforts to establish student communities of practice in the first year of an undergraduate programme, using group activities and assignments. Benefits included enhanced student engagement and belonging, which could act as precursors to retention. Given competing demands facing many students (e.g. employment, caring responsibilities, commuting), ring-fenced opportunities for peer interaction, within the scheduled timetable, are likely to be important. Here, contemporary approaches to delivery could preserve class time for work in smaller groups. Using the flipped classroom, for example, students cover course material in advance of contact hours, 
(Bishop and Verleger 2013). In class, groups then discuss and apply ideas; the lecturer circling the space to provide advice and informal assessment. The active learning tasks that are likely to feature in these group settings are, furthermore, associated with enhanced student performance (e.g. problem-solving, ResponseWare, worksheets; Freeman et al. 2014).

Caution is required, however. Approaches like the flipped classroom can rely on technology. For example, preparatory tasks in advance of contact hours might include reading material posted on a digital learning environment, or engaging with third party resources such as YouTube. Whilst predictor E was not associated with COW, the raw scores are notable. They indicate resistance amongst students to greater use of technologies. Although research by the National Union of Students (2010 39) offered somewhat different results, the authors note that the student population 'is at times contradictory in its views and remains uncertain over some of the implications emerging from ICT (Information and Communications Technology)'. Alongside new technologies, modern teaching models already expect students to master a range of skills outside the supportive context of the classroom (e.g. time management; independent research; critical appraisal; peer discussion - online or face-toface). Proactive approaches to learning may be unfamiliar and challenging to some students. Indeed, the current data confirm that independent learning, whilst unrelated to $\mathrm{COW}$, poses a challenge to some first year undergraduates (predictor K).

\section{Volume of assessment}

Contemplation of withdrawal was higher amongst students who perceived the volume of assessment as excessive. Assessment has been described as the strongest lever in HE to influence student behaviours (Gibbs 1999). However, it is also considered to be the most consistent area of concern, continually receiving the lowest satisfaction scores in the UK National Student Survey. A growing body of evidence, gathered using the TESTA 
methodology (Transforming the Experience of Students Through Assessment), suggests that excessive assessment might be part of the problem (Jessop, El Hakim, and Gibbs 2014). Repeated use of summative assessment to examine the same learning outcomes has emerged across a host of different HEIs.

The TESTA originators advocate a readjustment; exchange of some summative assessment for frequent, low stakes formative assessment. This model has the potential to reduce perceptions of assessment as too onerous, whilst at the same time offering another means of dedicated support around assignments. It is again notable that the primary mechanism for informing course choice amongst prospective students (UNISTATS) provides information on summative assessment only (i.e. proportion of exams, coursework and practical demonstration). Greater visibility and understanding of formative assessment amongst (prospective) students might, in part, address concerns around their motivation to engage with tasks that do not formally contribute to the final mark.

\section{Limitations of the study}

It should be recognised that this study measured contemplation of withdrawal - a proxy - and not actual withdrawal. Although figures for actual withdrawal were useful in interpreting the validity of COW, the modest number of cases was too small to allow further quantitative analysis. Low incidence of withdrawal could be expected in a time-bounded study where some individuals may have left the institution prior to the survey opening. It does, however, epitomise the central challenge to investigation in this field. To analyse actual withdrawal one requires access to a vast student cohort. Furthermore, unlike student characteristics which are held on file (e.g. demographics, prior educational attainment) factors such as academic experiences require individuals' subjective responses. Students who withdraw from HE, often in haste or difficult circumstances, may be unable or unwilling to yield this information 
(Quinn 2013). This is demonstrated in the large Back on Course project (Rose-Adams 2012), where of the 22,000 actual leavers who were contacted, less than 4,000 agreed to become 'clients' and give information on their reasons for leaving HE. The current study joins the bulk of research in probing students about possible future withdraw (e.g. all of the case studies in the What Works? Student Retention \& Success programme, Thomas 2012a). This approach is likely to continue on pragmatic grounds, although any studies that elicit subjective data from a significant cohort of actual leavers are greatly welcomed. It is also worth noting that the same factors which propel a minority of students to withdraw might also be felt by the broader student body (Rowley, Hartley, and Larkin 2008), manifesting in impaired performance or satisfaction. As such, the current findings could be seen as a useful barometer of students' general feelings towards their academic experience.

COW shares some of the frailties of prevailing measures/concepts in this field. For example, it did not detect if a student's contemplation of withdrawal was accompanied by plans to undertake a new course at a different HEI (a failing of retention) or to return to the host institution after a sustained absence (an issue with both retention and completion). Quinn (2013) offers a helpful model, which consolidates a comprehensive range of student outcomes (e.g. progress between years of a programme; transfer to an alternative course; withdrawal from HE within a given timeframe without achieving graduation). In future, investigators should select carefully the wording of surveys etc. so as to be able to identify different student narratives.

In the current study a $p$ value of $<.10$ was used to identify variables with significant associations to COW. Imagining that the study was repeated numerous times, this means that the reported effects could have been produced by random sampling error in up to $10 \%$ of occasions. It is important here to recall the overarching aim of the current study. As a crosssectional investigation causality could not be demonstrated. Rather, the purpose was to cast a 
relatively broad net and capture those academic experiences with the most likely links to withdrawal. These factors could then be examined using more exacting approaches, which have the capacity to demonstrate causality (e.g. case-control studies, cohort designs). The application of different $p$ values (e.g. <.05, <.01) would provide more assurance that effects were not random. However, it would also risk discarding academic experience variables where there appears a legitimate case for further investigation. Furthermore, for academics and administrators student withdrawal and the academic experiences examined here are not abstract areas of interest. Frequently, these stakeholders face unavoidable operational decisions around, for example, teaching methods; assessment design; use of learning technology; distribution of students' time between contact hours and independent study; personal tutoring provision; and limits on class size. Some authors have challenged a rigid weddedness to statistical conventions (e.g. $p$ values of <.05) instead proposing that 'initiatives in support of students' success have to be construed in probabilistic terms' (Yorke et al. 2015 104). This perspective has commonalities with Simon's (1957) concept of 'satisficing'. In the current context satisficing would mean that HE practitioners seek evidence that is 'good enough' to inform inescapable operational decisions. According to Yorke, Hoekstra and Turnbull (2015 102), 'Being "good enough" implies that...the likelihood that the analysis is not due to chance may fall some way short of the $p<.05$ level...the practicalities of institutional functioning may be satisfied by relatively slender odds - indeed, anything better than an even chance may suffice for practical action'.

The TLS items did not necessarily cover all academic experiences that students have in HE, or the other categories of predictor from Thomas's (2002) taxonomy. Efforts to establish an authoritative set of academic experiences and standardised instruments for investigating these would be welcomed. In broadening the search for predictors researchers should, however, be mindful of the complexity behind individuals' decisions to leave HE, which might make all- 
encompassing explanatory models elusive. Given the urgent need for some HEIs to enhance retention rates, Brunsden et al. (2000 307) note how 'research that focuses on single specific factors influencing dropout may have more practical utility'.

The response rate to the TLS was low, consistent with many large-scale online questionnaires used amongst student cohorts (Nulty 2008). Importantly, the profile of respondents' gender, age and faculty/school suggest that the sample was representative of the wider population at the institution. Moreover, the sample size comfortably exceeded the guiding principle for logistic regression, of at least 10 cases for each independent variable (Peduzzi et al. 1996). The data do, of course, relate to a single HEI. There would be value in examining the same kind of academic experiences at multiple institutions, so as to corroborate the findings and establish if relationships differ according to type of institution (e.g. high versus low entry tariff) or between territories.

A final word of caution is offered regarding the translation of these research findings into practical applications. Withdrawal is only one of the outcomes that HEIs must oversee, and a single initiative might have diverse effects on different metrics. For example, overall contact time with staff which was, here, unconnected to withdrawal, is strongly associated with student perceptions of value for money (Neves and Hillman 2016). Clearly, there is a need for HEIs to be judicious in how they interpret and act upon the increasing quantitative data that they have access to.

\section{Conclusions}

The current study showed significant associations between potentially modifiable academic experiences and contemplation of withdrawing from a HE programme. On their own, these variables accounted for between $5.6 \%$ and $7.8 \%$ of the variance in respondents' contemplation of withdrawal. This exceeds the variance explained in other studies which, for 
example, focussed on students' psychosocial characteristics (Ting and Robinson 1998). Specifically, the findings indicate a need to consider methods for increasing one-to-one contact with lecturing staff, and interactions between students. The results also support strong pre-entry and induction processes to prepare students for teaching approaches that they will encounter in HE. Finally, there appears to be value in a continued focus on assessment, to ensure that students can demonstrate knowledge and skill without being overwhelmed by the demands upon them. Although the findings have been discussed in relation to the UK context Thomas and Hovdhaugen (2014 459) note that 'many issues in HE transcend national boundaries and students across Europe are likely to experience both similar and different challenges with regard to being "successful" in HE'. The academic experiences that were examined in the current study are near ubiquitous across national HE systems. Furthermore, many countries have more troubling figures for retention/completion than the UK (OECD, 2014), suggesting a need to examine all possible avenues for improvement. The findings now support exploration of the highlighted academic experiences using alternative methods to determine if their relationship to withdrawal is causal.

\section{Acknowledgements:}

None

\section{Declaration of interest statement:}

None 


\section{References}

Arulampalam, W., R.A. Naylor, and J.P. Smith. 2005. "Effects of In-class Variation and

Student Rank on the Probability of Withdrawal: Cross-section and Time-series Analysis for

UK University Students.” Economics of Education Review 24 (3): 251-262.

Berger, J. B., and J.M. Braxton, J. M. 1998. "Revising Tinto's Interactionalist Theory of Student Departure Through Theory Elaboration: Examining the Role of Organizational Attributes in The Persistence Process." Research in Higher Education 39 (2): 103-119.

Bishop, J. L., and M.A. Verleger. 2013. "The Flipped Classroom: A Survey of the Research.” Paper presented at the annual conference and exposition of the American Society for Engineering Education, Atlanta, June 23-26.

Bourdieu, P. 1986. “The Forms of Capital.” In The Handbook of Theory: Research for the Sociology of Education, edited by J.G. Richardson, 241-258. New York: Greenwood Press.

British Council. 2014. Massification of Higher Education in Large Academic Systems: Summary Report. London: British Council.

Brunsden, V., M. Davies, M. Shevlin, and M. Bracken. 2000. "Why do HE Students Drop Out? A Test of Tinto's Model." Journal of Further and Higher Education 24(3): 301-310.

Charlton, J. P., C. Barrow, and P. Hornby-Atkinson. 2006. “Attempting to Predict Withdrawal From Higher Education Using Demographic, Psychological and Educational Measures. Research in Post-Compulsory Education 11 (1): 31-47.

Christie, H., P. Barron, and N. D'Annunzio-Green, N. 2013. "Direct entrants in transition: becoming independent learners." Studies in Higher Education 38 (4): 623-637. 
Cohen. J. 1988. Statistical Power Analysis for the Behavioral Sciences (2nd ed.). Hillsdale, NJ: Lawrence Erlbaum.

Cotton, D.R.E., T. Nash, and P. Kneale. 2017. "Supporting the Retention of Non-Traditional Students in Higher Education Using a Resilience Framework." European Education Research Journal 16 (1): 62-79.

Cotton, D. R., P. Nash, and P.E. Kneale. 2014. "The Experience of Care Leavers in UK Higher Education.” Widening Participation and Lifelong Learning 16 (3): 5-21.

Earwaker, J. 1992. Helping and Supporting Students. Buckingham: SRHE-OUP.

Field, A. 2005. Discovering Statistics Using SPSS. London: Sage publications.

Freeman, S., S.L. Eddy, M. McDonough, M. K. Smith, N. Okoroafor, H. Jordt, and M.P. Wenderoth. 2014. “Active Learning Increases Student Performance in Science, Engineering, and Mathematics." Proceedings of the National Academy of Sciences 111 (23): 8410-8415.

Giannakis, M., and N. Bullivant. 2016. "The Massification of Higher Education in the UK: Aspects of Service Quality.” Journal of Further and Higher Education 40 (5): 630-648.

Gibbs, G. 1999. “Using Assessment Strategically to Change the Way Students Learn” In Assessment Matters in Higher Education, edited by Brown, S., and A. Glasner. Buckingham: Society for Research into Higher Education and Open University Press

Gibbs, G. (2010). Dimensions of Quality. York: Higher Education Academy.

Hagenauer, G., and S.E. Volet. 2014. "Teacher-Student Relationship at University: An Important yet Under-Researched Field.” Oxford Review of Education 40 (3): 370-388.

HEFCE (Higher Education Funding Council for England). 2016. Teaching Excellence Framework: Year Two Additional Guidance. Bristol: HEFCE. 
Jessop, T., Y. El Hakim, and G. Gibbs. 2014. "The Whole is Greater than the Sum of its Parts: A Large-Scale Study of Students' Learning in Response to Different Programme Assessment Patterns." Assessment and Evaluation in Higher Education 39 (1): 73-88.

Longden, B. 2004. "Interpreting Student Early Departure from Higher Education Through the Lens of Cultural Capital”. Tertiary Education \& Management 10 (2): 121-138.

McCaig, C. 2016. "The Retreat from Widening Participation? The National Scholarship Programme and New Access Agreements in English Higher Education”. Studies in Higher Education 41 (2): 215-230.

McGivney, V. 1996. "Staying or Leaving the Course: Non-Completion and Retention." Adults Learning 7 (6): 133-135.

Masika, R., and J. Jones. 2016. "Building Student Belonging and Engagement: Insights into Higher Education Students' Experiences of Participating and Learning Together.” Teaching in Higher Education 21 (2): 138-150.

NAO (National Audit Office). 2007. Staying the Course: The Retention of Students in Higher Education. Report by The Comptroller and Auditor General. London: The Stationary Office.

NUS (National Union of Students). 2010. Student Perspectives on Technology-Demand, Perceptions and Training Needs. Report to HEFCE by NUS. London: NUS.

NUS (National Union of Students). 2012. Student Experience Research 2012 Part 2: Independent Learning and Contact Hours. London: NUS.

Neves, J., and N. Hillman. 2016. The 2016 Student Academic Experience Survey. York: Higher Education Academy. 
Nulty, D. D. 2008. "The Adequacy of Response Rates to Online and Paper Surveys: What Can Be Done?” Assessment and Evaluation in Higher Education 33 (3): 301-314.

OECD (Organisation for Economic Co-operation and Development). 2014. Education at a Glance 2014: OECD Indicators. Paris: OECD Publishing.

Peduzzi, P., J. Concato, E. Kemper, T.R. Holford, and A.R. Feinstein. 1996. “A Simulation Study of the Number of Events Per Variable in Logistic Regression Analysis." Journal of Clinical Epidemiology 49 (12): 1373-1379.

Quinn, J. 2013. Drop-Out and Completion in Higher Education in Europe Among Students from Under-Represented Groups. Brussels: DG Education and Culture, European Commission.

Richardson, S., and A. Radloff. 2014. “Allies in Learning: Critical Insights into the Importance of Staff-Student Interactions in University Education." Teaching in Higher Education 19 (6): 603-615.

Robbins, S. B., K. Lauver, H. Le, D. Davis, R. Langley, and A. Carlstrom. 2004. “Do Psychosocial and Study Skill Factors Predict College Outcomes? A Meta-Analysis.” Psychological Bulletin 130 (2): 261-288.

Rose-Adams, J. 2012. Leaving University Early: A Research Report from the Back on Course project. Milton Keynes: The Open University.

Rose-Adams, J. 2013. "Leaving University Early: Exploring Relationships Between Institution Type and Student Withdrawal and Implications for Social Mobility." Widening Participation and Lifelong Learning 15 (2): 96-112. 
Rowley, M., J. Hartley, and D. Larkin. 2008. "Learning from Experience: The Expectations and Experiences of First-Year Undergraduate Psychology Students." Journal of Further and Higher Education 32 (4): 399-413.

Simon, H.A. 1957. Models of Man. New York: Wiley.

Soria, K. M., and M.J. Stebleton. 2012. "First-Generation Students' Academic Engagement and Retention." Teaching in Higher Education 17 (6): 673-685.

Thomas, L. 2002. "Student Retention in Higher Education: The Role of Institutional Habitus.” Journal of Education Policy 17 (4): 423-442.

Thomas, L. 2012a. Building Student Engagement and Belonging in Higher Education at a Time of Change: Final Report from The What Works? Student Retention \& Success Programme. London: Paul Hamlyn Foundation.

Thomas, L. 2012b. Building Student Engagement and Belonging in Higher Education at a Time of Change: A Summary of Findings and Recommendations from The What Works? Student Retention \& Success Programme. London: Paul Hamlyn Foundation.

Thomas, L., and E. Hovdhaugen. 2014. "Complexities and Challenges of Researching Student Completion and Non-completion of HE Programmes in Europe: A Comparative Analysis Between England and Norway.” European Journal of Education 49 (4): 457-470.

Thomas, L., and J. Quinn. 2007. First Generation Entrants in Higher Education: An International Analysis. Maidenhead: Society for Research in Higher Education and Open University Press. 
Ting, S. M. R., and T.L. Robinson. 1998. "First-Year Academic Success: A Prediction Combining Cognitive and Psychosocial Variables for Caucasian and African American Students." Journal of College Student Development 39 (6): 599-610.

Tinto, V. 1975. "Dropout from Higher Education: A Theoretical Synthesis of Recent Research." Review of Educational Research 45 (1): 89-125.

Turner, R., D. Morrison, D. Cotton, S. Child, S Stevens, P. Nash, and P. Kneale. 2017. "Easing the Transition of First Year Undergraduates Through an Immersive Induction Module. Teaching in Higher Education 22(7); 805-821.

van Stolk, C., J. Tiessen, J. Clift, and R. Levitt. 2007. Student Retention in Higher Education Courses. International Comparison. Report Prepared for The National Audit Office. Cambridge: RAND Corporation.

Webb, O.J., L. Wyness, and D.R.E. Cotton. 2017. Enhancing Access, Retention, Attainment and Progression in Higher Education: A Review of the Literature Showing Demonstrable Impact. York: Higher Education Academy.

Whitty, G., A. Hayton, and S. Tang. 2015. "Who You Know, What You Know and Knowing the Ropes: A Review of Evidence About Access to Higher Education Institutions in England." Review of Education 3 (1): 27-67.

Willcoxson, L., J. Cotter, and S. Joy. 2011. "Beyond the First-Year Experience: The Impact on Attrition of Student Experiences Throughout Undergraduate Degree Studies in Six Diverse Universities." Studies in Higher Education 36 (3): 331-352.

Yorke, M., P Hoekstra, and W. Turnbull. 2015. "Maximising the Use of Institutional Data." In Stepping up to the Second Year at University, edited by Milsom, C., M Stewart, M. Yorke, and E. Zaitseva. Abingdon: Routledge. 
Yorke, M., C Milson, M. Stewart, and E. Zaitseva. 2015. "Listening for Signals in the Noise and Acting on Them." In Stepping up to the Second Year at University, edited by Milsom, C., M Stewart, M. Yorke, and E. Zaitseva. Abingdon: Routledge. 